\title{
INFLUÊNCIA DAS CONDIÇÕES DE SUPERFÍCIE E DO CULTIVO DO SOLO NA EROSÃO HÍDRICA EM UM CAMBISSOLO HÚMICO(1)
}

\author{
Júlio César Ramos ${ }^{(2)}$, Ildegardis Bertol ${ }^{(3)}$, Fabrício Tondello Barbosa ${ }^{(4)}$, Juliana \\ Marioti $^{(5)}$ \& Romeu de Souza Werner ${ }^{(6)}$
}

\section{RESUMO}

A cobertura do solo por resíduos culturais dissipa a energia cinética das gotas de chuva, enquanto a rugosidade superficial dissipa a energia cinética da enxurrada; por isso, ambas armazenam água e retêm sedimentos na superfície, diminuindo a erosão hídrica. $O$ objetivo deste estudo foi determinar a persistência e a influência dos resíduos culturais e da rugosidade superficial em solo cultivado nas perdas de solo e água, comparando ao solo sem cultivo e descoberto, nos seguintes tratamentos: solo cultivado - coberto por resíduos de azevém (Lolium multiflorum), com rugosidade mínima (SRA); coberto por resíduos de ervilhaca (Vicia sativa), com rugosidade mínima (SRE); escarificado após o cultivo de azevém sem os resíduos culturais da parte aérea e mantendo-se apenas as raízes da cultura, com rugosidade alta (SEA); escarificado após o cultivo de ervilhaca sem os resíduos culturais da parte aérea e mantendo-se apenas as raízes da cultura, com rugosidade alta (SEE); e solo sem cultivo: sem cobertura, escarificado, com rugosidade alta (SDE). $\mathrm{O}$ experimento foi desenvolvido entre maio de 2011 e dezembro de 2012, em parcelas com $11 \mathrm{~m}$ de comprimento no sentido do declive por $3,5 \mathrm{~m}$ de largura. Sobre os tratamentos, aplicaram-se oito testes de chuva simulada, em oito datas distintas, com chuvas de $90 \mathrm{~min}$ de duração e $65 \mathrm{~mm} \mathrm{~h}^{-1}$ de intensidade constante, utilizandose um simulador de chuva com braços rotativos do tipo empuxo. A massa de resíduos e a rugosidade diminuíram ao longo do tempo, principalmente nos tratamentos com ervilhaca, com maior decréscimo na primeira chuva para a rugosidade e na segunda, para o resíduo. $O$ cultivo diminuiu as perdas de solo em relação ao solo sem cultivo, independentemente das condições de superfície. Os resíduos de

(1) Parte da Dissertação de Mestrado do primeiro autor. Recebido para publicação em 22 de agosto de 2013 e aprovado em 10 de junho de 2014.

(2) Doutorando em Ciência do Solo, Centro de Ciências Agroveterinárias, Universidade do Estado de Santa Catarina - CAV/ UDESC. Av. Luis de Camões, 2090. CEP 88520-000 Lages (SC). E-mail: julio.ramos.ta@gmail.com

(3) Professor, Departamento de Solos, CAV/UDESC. Bolsista PQ/CNPq. E-mail: a2ib@cav.udesc.br

(4) Professor, Departamento de Solos, CAV/UDESC. E-mail: fabriciotondello@gmail.com

(5) Doutoranda em Ciência do Solo, Universidade Federal do Paraná. Rua dos Funcionários, 1540, Cabral. CEP 80035-050 Curitiba (PR). E-mail: julianamarioti@gmail.com

(6) Doutorando em Ciência do Solo, UDESC/CAV. E-mail: tiomema@msn.com 
azevém e ervilhaca reduziram as perdas de solo em relação aos tratamentos escarificados; já o resíduo de azevém reduz as perdas em relação ao de ervilhaca, independentemente do manejo do solo. As perdas de solo aumentam com o tempo sob cultivo do solo, principalmente com escarificação. As perdas de água apresentam a mesma tendência das perdas de solo, porém com menores diferenças entre tratamentos.

Termos de indexação: cobertura do solo, perdas de água, perdas de solo, rugosidade superficial.

\section{SUMMARY: INFLUENCE OF THE SURFACE CONDITIONS AND SOIL CULTIVATION ON WATER EROSION IN AN INCEPTISOL}

The soil cover by crop residues dissipates the kinetic energy of raindrops, while, the surface roughness dissipates the kinetic energy of runoff, therefore, both store water and retain sediments on surface, decreasing water erosion. The objective of this study was to determine the persistence and the influence of crop residues and surface roughness in cultivated soil on soil and water losses, compared to bare and uncovered soil under the following treatments: i) cultivated soil: covered by ryegrass mulch (Lolium multiflorum), with minimal roughness (RMC); covered by vetch mulch (Vicia sativa), with minimal roughness (VMC); chiseled after ryegrass cultivation in the absence of residues above-ground crop and presence of plant roots, with high roughness (RHR); chiseled after the vetch cultivation in the absence of above-ground crop residues and presence of plant roots, with high roughness (RHV); ii) bare soil: uncovered, chiseled, with high roughness (RHU). The experiment was carried out from May 2011, to December 2012, in experimental plots of $38.5 \mathrm{~m}^{2}(11 \mathrm{~m}$ along the slope and $3.5 \mathrm{~m}$ width). In these treatments, eight simulated rainfall testes were applied, with 90 min of duration and planned to a constant rain intensity of $65 \mathrm{~mm} \mathrm{~h}^{-1}$, using a rotating boom simulator rainfall moved by hydraulic thrust. The residue mass and the surface soil roughness decrease over time, especially in the vetch treatments, with more intense decrease in soil roughness in the first simulated rainfall test and in residues mass in the second rainfall test. The cultivation decreases soil losses relative to bare chiseled soil, independent of the surface conditions. Ryegrass and vetch residues reduce soil losses relative to chiseled treatments, and ryegrass reduces soil losses relative to vetch, independent of the soil management. The cultivated treatments show increasing soil loss during the time, mainly when soil was chiseled. The water losses by runoff follow the same tendency of soil losses, however, with lower differences between treatments.

Index terms: surface roughness, soil cover, soil loss, water loss.

\section{INTRODUÇÃO}

A erosão hídrica do solo, fenômeno ocasionado pelos agentes erosivos, caracteriza-se pela desagregação, pelo transporte e pela deposição e pode ser induzida pela atividade humana no caso da erosão acelerada (Ellison, 1947). A magnitude da erosão depende da inter-relação dos fatores que a influenciam, ou seja, o clima, o solo, o relevo, a cobertura e o manejo do solo e as práticas conservacionistas complementares (Wischmeier \& Smith, 1978). Entre esses fatores, o fator cobertura e manejo do solo (fator C da Equação Universal de Perda de Solo - USLE) é o mais importante, porque influencia mais fortemente o resultado da erosão (Wischimeier \& Smith, 1978).

Os sistemas de manejo conservacionista do solo, representados principalmente pela semeadura direta e pelo cultivo mínimo, caracterizam-se respectivamente pela ausência quase que completa de preparo e pelo preparo parcial do solo. Isso resulta numa elevada cobertura superficial no caso da semeadura direta e numa elevada rugosidade superficial, no caso do cultivo mínimo (Cogo, 1981).

A cobertura do solo por resíduos culturais é eficiente no controle da erosão hídrica, pois dissipa a energia cinética das gotas de chuva, evitando que essas impactem diretamente sobre o solo e desagreguem as partículas. Com isso, a cobertura evita o encrostamento da superfície do solo (Bertol et al., 1989), mantém alta infiltração de água no solo (Lopes et al., 1987a) e diminui o escoamento superficial (Cogo, 1981).

Além de diminuir o volume de água da enxurrada, a cobertura do solo por resíduos culturais diminui a velocidade e, com isso, a energia de desagregação e transporte de sedimentos do escoamento superficial (Mannering \& Meyer, 1962). Ademais, os resíduos aprisionam os sedimentos nos espaços existentes entre suas peças (Lopes et al., 1987b), diminuindo o diâmetro médio dos agregados transportados pelo escoamento superficial e, com 
isso, reduzindo as perdas de solo (Lopes et al., 1987a; Mello et al., 2003).

Os resíduos culturais e as raízes das plantas desempenham importante papel no aumento do teor de matéria orgânica no solo (Volk \& Cogo, 2009), contribuindo para a formação de agregados estáveis, graças à ação cimentante e aglutinante da matéria orgânica (Brandão \& Silva, 2012). Entre as espécies vegetais cultivadas, as gramíneas são mais eficientes na formação e no aumento da estabilidade dos agregados que as leguminosas, proporcionando maior resistência do solo à erosão (Dechen et al., 1981), em razão da sua alta densidade de raízes finas, as quais promovem a aproximação das partículas pela grande pressão exercida ao crescerem, bem como absorvem grande quantidade de água do solo.

A rugosidade representa o enrugamento da superfície do solo, sendo caracterizada pelo conjunto das microelevações e microdepressões do terreno, espacialmente distribuídas (Correa et al., 2012). O preparo do solo por meio de implementos agrícolas é a forma mais rápida e prática de se alterar a rugosidade superficial por causa do revolvimento e consequente afrouxamento do solo pela mobilização mecânica. Consequentemente, o aumento da rugosidade superficial ocasiona aumento da porosidade interna do solo (Allmaras et al., 1966), aumentando, dessa forma, a capacidade do solo de armazenamentos interno e externo de água, nas depressões de sua superfície (Allmaras et al., 1966), e, consequentemente, de infiltração de água no solo (Eltz \& Norton, 1997; Mello et al., 2003).

Segundo Bertol et al. (1989), com o aumento da rugosidade superficial do solo, há diminuição da erosão hídrica em razão da retenção da água e dos sedimentos nas microdepressões da superfície. Além disso, a rugosidade do solo apresenta grande importância na redução da velocidade do escoamento superficial e na sua capacidade de desagregar o solo (Eltz \& Norton, 1997).

Este trabalho teve por objetivos avaliar a influência do tipo de cultivo sobre a rugosidade superficial, cobertura do solo e massa de resíduos culturais; o efeito da rugosidade superficial e da cobertura do solo nas perdas de solo e água; e o efeito da erosividade da chuva sobre a persistência temporal dos resíduos e da rugosidade; e estabelecer relações entre as seguintes variáveis: rugosidade ao acaso com erosividade da chuva; massa de resíduos com tempo; perdas de solo com erosividade da chuva; cobertura do solo e rugosidade ao acaso com as perdas de solo; e cobertura do solo com massa de resíduos.

\section{MATERIAL E MÉTODOS}

Esta pesquisa foi desenvolvida no sul do Brasil em local com coordenadas de $27^{\circ} 47^{\prime}$ latitude sul e $50^{\circ} 18^{\prime}$ longitude oeste de Greenwich. O clima da região, segundo a classificação de Köppen, é do tipo Cfb, e a precipitação pluvial média anual, segundo Schick et al. (2014), é de $1.533 \mathrm{~mm}$. O relevo da área experimental é suave-ondulado, e a altitude do local do experimento é de aproximadamente $900 \mathrm{~m}$.

O solo da área experimental é um Cambissolo Húmico alumínico léptico (Embrapa, 1999), da classe textural franco-argilossiltosa. Coletaram-se amostras não deformadas para determinar a porosidade e densidade aparente, e amostras deformadas para a textura, a densidade das partículas, a estabilidade de agregados em água e o teor de carbono orgânico total, nas camadas de $0,00-0,025 ; 0,025-0,05 ; 0,05-0,10$; 0,10-0,15; e 0,15-0,20 m, cujos resultados encontramse no quadro 1.

No último ciclo cultural anteriormente à instalação do experimento, a área era manejada sob semeadura direta (com exceção de onde foram instaladas as parcelas descobertas), com cultivos de soja (Glycine max) e milho (Zea mays) no sentido do declive e em contorno. Ao final desse ciclo, retiraram-se os resíduos culturais e as culturas de azevém e ervilhaca foram semeadas de forma manual e a lanço, sendo as sementes incorporadas ao solo com uma gradagem leve no sentido transversal ao declive.

A unidade experimental, ou parcela, media $11 \mathrm{~m}$ de comprimento no sentido do declive e $3,5 \mathrm{~m}$ de largura $\left(38,5 \mathrm{~m}^{2}\right)$, segundo IAPAR (1975). Cada parcela era delimitada nas laterais e na extremidade superior por chapas galvanizadas de $0,2 \mathrm{~m}$ de altura cravadas $0,1 \mathrm{~m}$ no solo; e na extremidade inferior por uma calha coletora conectada a um tubo de PVC de $75 \mathrm{~mm}$ de diâmetro e $6 \mathrm{~m}$ de comprimento, que direcionava o fluxo do escoamento até uma trincheira onde se realizavam as medições e coletas da enxurrada. As parcelas tinham declividade variando de $0,124 \mathrm{~m} \mathrm{~m}^{-1}$ a $0,145 \mathrm{~m} \mathrm{~m}^{-1}$, com média de $0,134 \mathrm{~m} \mathrm{~m}^{-1}$.

Estudaram-se os seguintes tratamentos: a) cultivo de azevém (Lolium multiflorum), sem preparo do solo, com o resíduo cultural totalmente mantido na superfície, e a rugosidade era mínima (SRA); b) cultivo de ervilhaca (Vicia sativa), sem preparo do solo, com o resíduo cultural totalmente mantido na superfície, e a rugosidade era mínima (SRE). Nesses dois tratamentos, a rugosidade era resultante de uma gradagem leve realizada no ato da semeadura da cultura para incorporação das sementes; c) cultivo de azevém, onde o resíduo cultural foi totalmente removido da superfície, mantendo-se apenas as soqueiras da cultura, e o solo foi preparado com uma escarificação (SEA); d) cultivo de ervilhaca, onde o resíduo cultural foi totalmente removido da superfície, mantendo-se apenas as soqueiras da cultura, e o solo foi preparado com uma escarificação (SEE); e e) solo sem cultivo e sem resíduo cultural, assim mantido por mais de dois anos e preparado com uma escarificação (SDE). Nos tratamentos SEA e SEE, as culturas foram roçadas na plena floração para a retirada dos resíduos, e a operação de escarificação foi realizada, inclusive no SDE, em 13 de dezembro de 
Quadro 1. Teores de areia (AR), silte (SI), argila (AG) e carbono orgânico (CO), densidade do solo (Ds), densidade das partículas (Dp), porosidade total (PT), macroporosidade (MA), microporosidade (MI) e estabilidade dos agregados em água (DMP) para as camadas de 0,00-0,025; 0,025-0,05; 0,05-0,10; e 0,10$0,20 \mathrm{~m}$ do solo, em cada um dos tratamentos (média das repetições)

\begin{tabular}{|c|c|c|c|c|c|c|c|c|c|c|}
\hline Camada & AR & SI & $\mathbf{A G}$ & $\mathrm{CO}$ & Ds & Dp & PT & MI & MA & DMP \\
\hline \multirow[t]{2}{*}{$\mathrm{m}$} & 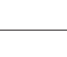 & $\mathrm{g} \mathrm{kg}^{-1}$ & 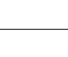 & $\%$ & \multicolumn{2}{|c|}{$-\mathrm{kg} \mathrm{dm}^{-3}$} & 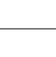 & $-\%$ & 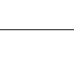 & $\mathrm{mm}$ \\
\hline & \multicolumn{10}{|c|}{ SRA } \\
\hline $0,00-0,025$ & 190 & 420 & 390 & 3,1 & 1,07 & 2,45 & 58 & 36 & 22 & 5,8 \\
\hline $0,025-0,05$ & 186 & 418 & 396 & 2,7 & 1,08 & 2,45 & 55 & 35 & 20 & 5,6 \\
\hline $0,05-0,10$ & 189 & 413 & 398 & 2,5 & 1,35 & 2,38 & 50 & 44 & 6 & 6,2 \\
\hline \multirow[t]{2}{*}{$0,10-0,20$} & 172 & 421 & 407 & 2,6 & 1,31 & 2,41 & 48 & 44 & 4 & 6,0 \\
\hline & \multicolumn{10}{|c|}{ SRE } \\
\hline $0,00-0,025$ & 238 & 414 & 348 & 3,1 & 1,07 & 2,38 & 56 & 31 & 25 & 5,9 \\
\hline $0,025-0,05$ & 181 & 429 & 390 & 2,9 & 1,42 & 2,40 & 50 & 42 & 8 & 5,9 \\
\hline $0,05-0,10$ & 174 & 412 & 414 & 2,8 & 1,39 & 2,31 & 51 & 43 & 8 & 6,2 \\
\hline \multirow[t]{2}{*}{$0,10-0,20$} & 184 & 383 & 433 & 2,6 & 1,35 & 2,53 & 50 & 44 & 6 & 5,9 \\
\hline & \multicolumn{10}{|c|}{ SEA } \\
\hline $0,00-0,025$ & 227 & 425 & 348 & 3,0 & 1,23 & 2,35 & 51 & 40 & 11 & 5,8 \\
\hline $0,025-0,05$ & 211 & 415 & 374 & 2,8 & 1,33 & 2,37 & 50 & 41 & 9 & 5,9 \\
\hline $0,05-0,10$ & 207 & 417 & 376 & 2,5 & 1,33 & 2,47 & 50 & 43 & 7 & 6,2 \\
\hline \multirow[t]{2}{*}{$0,10-0,20$} & 202 & 411 & 387 & 2,5 & 1,31 & 2,46 & 51 & 46 & 5 & 6,2 \\
\hline & \multicolumn{10}{|c|}{ SEE } \\
\hline $0,00-0,025$ & 206 & 425 & 369 & 2,7 & 1,21 & 2,50 & 52 & 36 & 16 & 6,0 \\
\hline $0,025-0,05$ & 192 & 410 & 398 & 2,6 & 1,43 & 2,51 & 48 & 40 & 8 & 6,2 \\
\hline $0,05-0,10$ & 198 & 436 & 366 & 2,5 & 1,35 & 2,47 & 48 & 40 & 8 & 6,1 \\
\hline \multirow[t]{2}{*}{$0,10-0,20$} & 198 & 431 & 371 & 2,2 & 1,35 & 2,51 & 49 & 43 & 6 & 5,8 \\
\hline & \multicolumn{10}{|c|}{ SDE } \\
\hline $0,00-0,025$ & 151 & 427 & 422 & 2,3 & 1,07 & 2,53 & 59 & 35 & 24 & 5,6 \\
\hline $0,025-0,05$ & 207 & 376 & 417 & 2,4 & 1,05 & 2,49 & 59 & 34 & 25 & 5,4 \\
\hline $0,05-0,10$ & 206 & 377 & 417 & 2,4 & 1,22 & 2,54 & 53 & 44 & 9 & 5,5 \\
\hline $0,10-0,20$ & 207 & 373 & 420 & 2,5 & 1,19 & 2,59 & 54 & 46 & 8 & 5,3 \\
\hline
\end{tabular}

SRA: solo coberto por resíduo de azevém; SRE: solo coberto por resíduo de ervilhaca; SEA: solo escarificado com raiz de azevém; SEE: solo escarificado com raiz de ervilhaca; e SDE: solo descoberto escarificado.

2012, em contorno ao declive, na profundidade de 0,15 $\mathrm{m}$, resultando em rugosidade alta. Os tratamentos constaram de duas repetições de campo.

Para a aplicação das chuvas, em número de oito por tratamento, utilizou-se um aparelho simulador de chuvas de braços rotativos tipo empuxo, cuja movimentação dos braços era feita pela ação do empuxo da água (Bertol et al., 2012), o qual cobria simultaneamente duas parcelas espaçadas entre si de $3,5 \mathrm{~m}$. As chuvas simuladas foram aplicadas com duração de $90 \mathrm{~min}$, e a intensidade planejada de $65 \mathrm{~mm} \mathrm{~h}^{-1}$ foi constante ao longo do tempo. Em cada dia era aplicado um teste, composto por cinco chuvas, uma sobre cada tratamento. $\mathrm{O}$ teste 1 foi aplicado em 17/12/2011; os demais foram aplicados respectivamente em 10/01/2012, 07/02/2012, 10/03/2012, 11/05/2012, 18/08/2012, 02/11/2012 e 18/12/2012, perfazendo, um ano entre os testes 1 e 8 .

As leituras da rugosidade superficial do solo foram feitas imediatamente antes e após o preparo do solo, antes de cada chuva simulada e ao final da última chuva simulada, apenas nos tratamentos SEA, SEE e SDE. As leituras foram feitas em um local, intermediário na parcela, onde foram cravadas estacas de madeira no solo para servir de suporte ao rugosímetro, de modo que as leituras eram feitas sempre no mesmo local e com o rugosímetro sempre na mesma altura em relação ao nível do terreno, utilizando-se um rugosímetro de varetas, conforme descrito por Correa et al. (2012). Esse método baseiase no registro fotográfico de um conjunto de 20 varetas, dispostas em 20 posições. A interpretação da rugosidade é com base na análise das imagens, conforme proposto por Liñares \& Castro (1998). As alturas das varetas das fotografias que representavam o microrrelevo foram obtidas por meio do uso do programa Profile Meter Program, proposto por Wagner \& Yiming (1991) e Wagner (1992), o qual detecta as alturas das varetas em fotografia com formato digital. $\mathrm{O}$ índice de rugosidade foi calculado pelo método proposto por Kamphorst et al. (2000), em 
que não se transformam os dados para logaritmo nem se eliminam os valores extremos, contando-se com a ajuda do programa computacional proposto por Miranda (2000).

Da mesma forma, antes de cada chuva simulada, determinou-se a cobertura do solo pelos resíduos culturais nos tratamentos SRA, SRE, SEA e SEE, pelo método da corda marcada como descrito por Sloneker \& Moldenhauer (1977). Também foi determinada a massa vegetal imediatamente antes de cada chuva simulada nos tratamentos SRA e SRE, com base em uma área de $0,36 \mathrm{~m}^{2}$, cujo resíduo foi coletado em uma única posição dentro da parcela, extrapolando o valor encontrado para 1 ha.

Imediatamente antes de iniciar as chuvas simuladas, coletaram-se amostras deformadas para determinar o teor de água do solo, nas camadas de 0,0-0,1 e 0,1-0,2 m de profundidade, calculado em base gravimétrica, conforme a fórmula a seguir:

$$
\mathrm{Ug}=\left[(\mathrm{mSU}-\mathrm{mSS}) \mathrm{mSS}^{-1}\right] \times 100
$$

em que Ug: umidade gravimétrica $\left(\mathrm{kg} \mathrm{kg}^{-1}\right) ; \mathrm{mSU}$ : massa de solo úmido (g); e mSS: massa de solo seco $(g)$.

Durante a chuva simulada, quantificou-se a taxa instantânea de enxurrada para calcular as perdas de solo e água, de acordo com método descrito por Cogo (1981). Após o início do escoamento, mediu-se a enxurrada a cada 5 min com a ajuda de uma proveta graduada e de um cronômetro, marcando o tempo necessário para se coletar um volume conhecido. Nesse mesmo momento, coletou-se a enxurrada em um pote plástico de $0,75 \mathrm{~L}$ para posterior determinação da concentração de solo e água na enxurrada.

Por meio de uma planilha de cálculo, calcularamse as taxas instantâneas de perdas de solo e água para intervalos de $1 \mathrm{~min}$ por interpolação linear dos valores de perdas quantificadas no campo a cada $5 \mathrm{~min}$. A quantidade total de solo perdida por erosão foi obtida pela integração das taxas instantâneas de perda de solo. Os dados de perdas totais de água e solo foram ajustados para a intensidade de chuva planejada de $65 \mathrm{~mm} \mathrm{~h}^{-1}$, conforme definido por Cogo (1981). A perda de água ajustada foi obtida com base na equação a seguir:

$$
\text { FCI }=i_{\text {planejada }} \times i_{\text {aplicada }}{ }^{-1}
$$

em que FCI: fator de correção da intensidade da chuva na perda de água; $i_{\text {planejada }}$ : intensidade de chuva planejada $\left(65 \mathrm{~mm} \mathrm{~h}^{-1}\right)$; e $\mathrm{i}_{\text {aplicada }}$ : intensidade real de chuva aplicada $\left(\mathrm{mm} \mathrm{h}^{-1}\right)$.

$\mathrm{O}$ ajuste das perdas de solo para a intensidade da chuva foi obtido elevando-se ao quadrado o resultado da divisão da intensidade da chuva pela intensidade da chuva aplicada, conforme a equação 3 :

$$
\text { FCI }=\left(i_{\text {planejada }} \times i_{\text {aplicada }}{ }^{-1}\right)^{2}
$$

em que FCI: fator de correção da intensidade na perda total de solo; $i_{\text {planejada }}$ intensidade de chuva planejada $\left(65 \mathrm{~mm} \mathrm{~h}^{-1}\right) ; \mathrm{i}_{\text {aplicada: }}$ : intensidade de chuva real ( $\mathrm{mm}$ $\left.\mathrm{h}^{-1}\right)$.

As perdas totais de solo foram corrigidas, ainda, para a declividade, padronizando-as para a declividade média das parcelas $\left(0,134 \mathrm{~m} \mathrm{~m}^{-1}\right)$, seguindo o proposto por Wischmeier \& Smith (1978), conforme a equação 4 :

$$
\mathrm{S}=0,065+4,56 \operatorname{sen} \theta+65,41(\operatorname{sen} \theta)^{2}
$$

em que S: fator declividade da USLE (Equação Universal de Perda de Solo); e $\theta$ : ângulo de declive do terreno.

A intensidade e o volume das chuvas aplicadas foram obtidos com o auxílio de 20 pluviômetros. Calcularam-se a erosividade (EI) das chuvas simuladas e a das chuvas naturais $\left(\mathrm{EI}_{30}\right)$, que ocorreram entre as chuvas simuladas (Quadro 2). Para o cálculo da EI das chuvas simuladas, utilizou-se a equação proposta por Meyer (1958):

$$
\mathrm{EI}=0,2083 \mathrm{Q} \mathrm{I}
$$

em que EI: erosividade das chuvas (MJ mm ha-1 $\left.\mathrm{h}^{-1}\right)$; Q: altura de chuva aplicada ( $\mathrm{mm})$; e I: intensidade da chuva aplicada $\left(\mathrm{mm} \mathrm{h}^{-1}\right)$.

$\mathrm{O}$ cálculo do $\mathrm{EI}_{30}$ das chuvas naturais foi feito para chuvas individuais, conforme descrito por Wischmeier \& Smith (1978), cotando-se as chuvas em segmentos de mesma intensidade e calculando-se a erosividade com base na equação desenvolvida por Foster et al. (1981):

$$
\mathrm{E}=0,119+0,0873 \log _{10} \mathrm{I}
$$

em que E: energia cinética por $\mathrm{mm}$ de chuva (MJ ha $\left.{ }^{-1} \mathrm{~mm}^{-1}\right)$; e I: intensidade da chuva $\left(\mathrm{mm} \mathrm{h}^{-2}\right)$.

$\mathrm{O}$ delineamento experimental utilizado foi o inteiramente casualizado. Os dados foram analisados por meio do pacote estatístico SAS (Statistical Analysis System) versão 9.2 para Windows ${ }^{\circledR}$, utilizando-se o procedimento MIXED (modelos mistos). Para a escolha da matriz de variância e covariância, utilizou-se o critério de informação de Akaike (Wolfinger, 1993). Assim, foi possível detectar os efeitos principais das causas de variação e a interação entre eles. O efeito de teste de chuva (época) foi considerado fixo e as variáveis respostas (perdas de solo, perdas de água, rugosidade superficial, massa de resíduos e cobertura do solo) efeito aleatório (Littel et al., 2000). A comparação entre as médias foi realizada por meio da probabilidade da diferença (PDIFF), utilizando-se o teste t de Student a $5 \%$. Ainda, realizaram-se relações para os seguintes dados: rugosidade superficial do solo versus $\mathrm{EI}_{30}$ acumulado; massa de resíduos culturais versus tempo; perdas de solo versus $\mathrm{EI}_{30}$ acumulado; perdas de solo versus cobertura do solo por resíduos culturais e versus rugosidade superficial do solo; e massa de resíduos versus a cobertura do solo por resíduos culturais. 
Quadro 2. Intensidade e altura das chuvas simuladas, aplicadas em cada tratamento, e altura de chuva natural até o período, bem como a erosividade $\left(\mathrm{EI}_{30}\right)$ das chuvas simuladas e naturais do período avaliado

\begin{tabular}{|c|c|c|c|c|c|c|}
\hline \multirow[t]{2}{*}{ Tratamento } & \multicolumn{2}{|c|}{ Chuva simulada } & \multirow{2}{*}{$\begin{array}{c}\mathbf{E I}_{30} \\
\mathrm{MJ} \mathrm{mm} \mathrm{ha}{ }^{-1} \mathrm{~h}^{-1}\end{array}$} & \multicolumn{2}{|c|}{ Chuva simulada } & \multirow{2}{*}{$\frac{\mathbf{E I}_{30}}{\mathrm{MJ} \mathrm{mm} \mathrm{ha}{ }^{-1} \mathrm{~h}^{-1}}$} \\
\hline & $\mathrm{mm} \mathrm{h}^{-1}$ & $\mathrm{~mm}$ & & $\mathrm{~mm} \mathrm{~h}^{-1}$ & $\mathrm{~mm}$ & \\
\hline & & Teste 1 & & & Teste 2 & \\
\hline SRA & 63 & 95 & 1.244 & 73 & 110 & 1.672 \\
\hline SRE & 60 & 91 & 1.147 & 73 & 109 & 1.647 \\
\hline SEA & 58 & 88 & 1.069 & 74 & 111 & 1.697 \\
\hline SEE & 61 & 92 & 1.166 & 74 & 111 & 1.721 \\
\hline SDE & 65 & 97 & 1.315 & 71 & 106 & 1.570 \\
\hline \multirow[t]{2}{*}{ Chuva natural } & - & - & - & - & 36 & 55 \\
\hline & & Teste 3 & & & Teste 4 & \\
\hline SRA & 63 & 94 & 1.241 & 63 & 94 & 1.239 \\
\hline SRE & 61 & 91 & 1.151 & 61 & 91 & 1.160 \\
\hline SEA & 60 & 91 & 1.144 & 57 & 86 & 1.022 \\
\hline SEE & 63 & 94 & 1.235 & 59 & 89 & 1.102 \\
\hline SDE & 58 & 87 & 1.042 & 63 & 943 & 1.233 \\
\hline \multirow[t]{2}{*}{ Chuva natural } & - & 203 & 784 & - & 119 & 210 \\
\hline & & Teste 5 & & & Teste 6 & \\
\hline SRA & 61 & 92 & 1167 & 63 & 95 & 1244 \\
\hline SRE & 60 & 90 & 1124 & 64 & 95 & 1260 \\
\hline SEA & 60 & 89 & 1111 & 65 & 98 & 1339 \\
\hline SEE & 61 & 91 & 1153 & 65 & 98 & 1323 \\
\hline SDE & 62 & 93 & 1193 & 64 & 97 & 1296 \\
\hline \multirow[t]{2}{*}{ Chuva natural } & - & 76 & 98 & - & 202 & 316 \\
\hline & & Teste 7 & & & Teste 8 & \\
\hline SRA & 65 & 97 & 1315 & 64 & 96 & 1276 \\
\hline SRE & 66 & 100 & 1379 & 65 & 98 & 1332 \\
\hline SEA & 68 & 102 & 1436 & 67 & 100 & 1390 \\
\hline SEE & 66 & 99 & 1371 & 65 & 98 & 1334 \\
\hline SDE & 68 & 101 & 1428 & 68 & 102 & 1453 \\
\hline Chuva natural & - & 184 & 790 & - & 41 & 141 \\
\hline
\end{tabular}

SRA: solo coberto por resíduo de azevém; SRE: solo coberto por resíduo de ervilhaca; SEA: solo escarificado com raiz de azevém; SEE: solo escarificado com raiz de ervilhaca; e SDE: solo descoberto escarificado.

\section{RESULTADOS E DISCUSSÃo}

Os teores de água gravimétrica no solo antecedente às chuvas variaram de $0,21 \mathrm{a} 0,27 \mathrm{~kg} \mathrm{~kg}^{-1}$ na camada de $0,0-0,1$ m e de 0,27 a $0,34 \mathrm{~kg} \mathrm{~kg}^{-1}$ na camada de 0,1-0,2 m, entre os tratamentos e na média dos testes de chuva (Quadro 3). O menor valor, na camada de 0,0-0,1 m do solo, foi $0,18 \mathrm{~kg} \mathrm{~kg}^{-1}$ no tratamento SRE (teste 2); e o maior, $0,34 \mathrm{~kg} \mathrm{~kg}^{-1}$, ocorrido nos tratamentos SRA e SRE (teste 3). Já para a camada de 0,1-0,2 m, o menor valor foi $0,22 \mathrm{~kg} \mathrm{~kg}^{-1}$ no SEE (teste 1); e o maior, $0,39 \mathrm{~kg} \mathrm{~kg}^{-1}$ no SDE (também no teste 1$)$.

Entre os tratamentos com cultivo o SRA manteve mais água na camada de 0,0-0,1 m do solo $\left(0,27 \mathrm{~kg} \mathrm{~kg}^{-1}\right.$ na média dos testes) do que os demais tratamentos, possivelmente pela diminuição da temperatura e do vento na superfície, pois os resíduos culturais cobriram o solo protegendo-o, concordando com Bertol et al. (2004). Já o tratamento cultivado que menos água manteve nessa camada do solo foi o SEE $\left(0,21 \mathrm{~kg} \mathrm{~kg}^{-1}\right.$ na média dos testes). O tratamento sem cultivo do solo (SDE) manteve maior teor no solo na camada de 0,1-0,2 m (0,34 $\left.\mathrm{kg} \mathrm{kg}^{-1}\right)$ do que os tratamentos com cultivo, pois a ausência de cultivo diminuiu a demanda de água do solo para a atmosfera no SDE.

Os resultados da análise estatística para variáveis respostas, rugosidade superficial ao acaso do solo, cobertura do solo por resíduos culturais, massa de resíduos culturais, perdas de solo e perdas de água, bem como o efeito dos testes de chuva sobre essas variáveis respostas e interação entre essas e os testes de chuva, estão apresentados no quadro 4 . Arugosidade ao acaso da superfície do solo (RR), a cobertura do solo por resíduos culturais (CS), a massa de resíduos culturais (MR), as perdas de solo (PS) e as perdas de 
água (PA) diferiram estatisticamente entre os tratamentos e entre os testes de chuva; houve interação entre rugosidade superficial do solo, cobertura do solo por resíduos culturais e perda de solo com os testes de chuva.

O valor de RR foi 4,1 $\mathrm{mm}$ antes do preparo, na média dos tratamentos, concordando com o encontrado por Bramorski et al. (2012); após a escarificação, o valor aumentou para 17,5 mm (Quadro 5), semelhante ao encontrado por Zoldan Junior et al. (2008) e Correa et al. (2012), ambos sob condição de solo preparado com escarificador. Na média dos testes de chuva, apenas o SDE diferiu o RR estatisticamente dos demais, com valor de $9 \mathrm{~mm}$, em comparação ao valor de 12,2 mm na média de SEA e SEE. O menor valor de RR no tratamento SDE, do que nos demais, após a aplicação de oito testes de chuva simulada, foi por causa da menor resistência do solo à desagregação. Isso se explica pela diminuição do teor de carbono orgânico; consequentemente menor estabilidade dos agregados em água (DMP) (Quadro 1), originada pela falta de cultivo em relação aos tratamentos cultivados.
O cultivo do solo nos tratamentos SEA e SEE proporcionou maior teor de matéria orgânica e ação das raízes das culturas, conferindo resistência do solo à desagregação, conforme verificado por Luciano et al. (2009) e Barbosa et al. (2010).

Após a escarificação (Quadro 5), o maior valor de $\mathrm{RR}$ foi encontrado no tratamento solo escarificado com raízes de azevém (SEA) $(20,5 \mathrm{~mm})$, seguido pelo tratamento solo escarificado com raízes de ervilhaca (SEE) $(17,4 \mathrm{~mm})$ e pelo solo descoberto escarificado (SDE) $(14,6 \mathrm{~mm})$, concordando com Volk \& Cogo (2009). Esses autores observaram melhoria das condições físico-estruturais do solo cultivado, refletindo-se na $\mathrm{RR}$, em relação ao solo mantido por longo tempo sem cultivo. $\mathrm{O}$ menor valor de RR no tratamento SDE explica-se pela superfície do solo que apresentou torrões menores que os demais tratamentos, pela desagregação pelo impacto das gotas de chuva, pelo constante revolvimento mecânico, pela falta de raízes e pelo menor teor de carbono orgânico (Quadro 1), segundo argumentado por Volk \& Cogo (2009). A maior rugosidade verificada no tratamento

Quadro 3. Teor de água no solo em base gravimétrica antecedente aos testes de chuva simulada (T) em cada tratamento, nas camadas de 0,0-0,10 e 0,10-0,20 m

\begin{tabular}{|c|c|c|c|c|c|c|c|c|c|}
\hline Tratamento & $\mathbf{T} 1$ & T 2 & T 3 & T 4 & T 5 & T 6 & $\mathrm{~T} 7$ & T 8 & Média \\
\hline SRA & 0,32 & 0,25 & 0,34 & 0,24 & 0,26 & 0,27 & 0,24 & 0,24 & 0,27 \\
\hline SRE & 0,30 & 0,18 & 0,34 & 0,27 & 0,23 & 0,24 & 0,28 & 0,24 & 0,26 \\
\hline SEA & 0,32 & 0,23 & 0,31 & 0,23 & 0,19 & 0,22 & 0,23 & 0,22 & 0,24 \\
\hline SEE & 0,20 & 0,20 & 0,28 & 0,22 & 0,20 & 0,21 & 0,19 & 0,21 & 0,21 \\
\hline SDE & 0,33 & 0,24 & 0,32 & 0,21 & 0,23 & 0,23 & 0,26 & 0,28 & 0,26 \\
\hline Média & 0,29 & 0,22 & 0,32 & 0,23 & 0,22 & 0,23 & 0,24 & 0,24 & \\
\hline SRA & 0,31 & 0,29 & 0,33 & 0,29 & 0,30 & 0,31 & 0,31 & 0,31 & 0,31 \\
\hline SRE & 0,28 & 0,27 & 0,35 & 0,31 & 0,31 & 0,30 & 0,32 & 0,32 & 0,31 \\
\hline SEA & 0,35 & 0,27 & 0,31 & 0,33 & 0,29 & 0,32 & 0,30 & 0,29 & 0,31 \\
\hline SEE & 0,22 & 0,25 & 0,27 & 0,30 & 0,28 & 0,32 & 0,27 & 0,25 & 0,27 \\
\hline SDE & 0,39 & 0,30 & 0,36 & 0,33 & 0,33 & 0,33 & 0,35 & 0,34 & 0,34 \\
\hline Média & 0,31 & 0,28 & 0,32 & 0,31 & 0,30 & 0,32 & 0,31 & 0,30 & \\
\hline
\end{tabular}

SRA: solo coberto por resíduo de azevém; SRE: solo coberto por resíduo de ervilhaca; SEA: solo escarificado com raiz de azevém; SEE: solo escarificado com raiz de ervilhaca; e SDE: solo descoberto escarificado.

Quadro 4. Análise estatística da variância correspondente aos cinco tratamentos, aos oito testes de chuva e à interação entre os tratamentos e aos testes para a rugosidade ao acaso da superfície do solo (RR), a massa de resíduos culturais (MR), a porcentagem de cobertura do solo por resíduos culturais (CS), as perdas de solo (PS) e as perdas de água (PA)

\begin{tabular}{|c|c|c|c|c|c|c|}
\hline \multirow{2}{*}{ Fonte de variação } & \multicolumn{6}{|c|}{ Significância $(p>F)$} \\
\hline & GL & $\mathbf{R R}$ & MR & CS & PS & PA \\
\hline Tratamento & 4 & $<0,0001^{*}$ & $<0,0001^{*}$ & $<0,0001^{*}$ & $<0,0001^{*}$ & $<0,0001^{*}$ \\
\hline Teste & 7 & $<0,0001^{*}$ & $<0,0001^{*}$ & $<0,0001^{*}$ & $<0,0001^{*}$ & $<0,0001^{*}$ \\
\hline Trat $\times$ teste & 28 & $0,0051^{*}$ & $0,4619^{\mathrm{ns}}$ & $<0,0001^{*}$ & $<0,0001^{*}$ & $0,5141^{\mathrm{ns}}$ \\
\hline
\end{tabular}

GL: grau de liberdade; ${ }^{\text {ns }} \mathrm{e}^{*}$ : não significativo e significativo a $5 \%$, respectivamente. 
Quadro 5. Valores de rugosidade ao acaso da superfície do solo (RR) de cada tratamento antes do preparo do solo (AP), em cada um dos testes de chuva simulada (T), e após o teste 8 de chuva (AT8), cobertura do solo por resíduos culturais e massa de resíduos nos diferentes tratamentos em cada teste de chuva simulada

\begin{tabular}{|c|c|c|c|c|c|c|c|c|c|c|c|}
\hline Tratamento & AP & T 1 & T 2 & T 3 & T 4 & T 5 & T 6 & $\mathrm{~T} 7$ & T 8 & AT8 & Média \\
\hline & \multicolumn{11}{|c|}{ Rugosidade (mm) } \\
\hline SEA & 4,7 & $20,5 \mathrm{Aa}$ & $15,5 \mathrm{Ab}$ & $14,0 \mathrm{Abc}$ & 12,3 Acd & 11,1 Acde & 10,1Ade & 9,7 Ade & $9,0 \mathrm{Ae}$ & $8,1 \mathrm{Ae}$ & $12,3 \mathrm{~A}$ \\
\hline SEE & 4,6 & $17,4 \mathrm{ABa}$ & 14,7 Aab & 11,9 Abcd & $12,5 \mathrm{Abc}$ & 11,4 Acd & 10,8 Acd & 10,4 Acd & 10,2 Acd & 9,3 Ad & $12,1 \mathrm{~A}$ \\
\hline SDE & 2,9 & $14,6 \mathrm{Ba}$ & 9,6 Bbc & $8,3 \mathrm{Bbc}$ & $8,4 \mathrm{Bbc}$ & $6,6 \mathrm{Bc}$ & $7,0 \mathrm{Bc}$ & $11,1 \mathrm{Ab}$ & $11,1 \mathrm{Ab}$ & $10,1 \mathrm{Ab}$ & $9,0 \mathrm{~B}$ \\
\hline \multirow[t]{2}{*}{ Média } & & $17,5 \mathrm{a}$ & $13,3 \mathrm{~b}$ & $11,4 \mathrm{c}$ & $11,1 \mathrm{~cd}$ & 9,7 cde & $9,3 \mathrm{de}$ & 10,4 cde & 10,1 cde & $9,2 \mathrm{e}$ & \\
\hline & \multicolumn{11}{|c|}{ Cobertura do solo (\%) } \\
\hline SRA & - & $100 \mathrm{Aa}$ & $98 \mathrm{Ab}$ & $97 \mathrm{Ab}$ & $99 \mathrm{Aab}$ & $89 \mathrm{Ac}$ & $57 \mathrm{Ad}$ & $44 \mathrm{Ae}$ & $31 \mathrm{Af}$ & - & $77 \mathrm{~A}$ \\
\hline SRE & - & $90 \mathrm{Bab}$ & $91 \mathrm{Ba}$ & $86 \mathrm{Bc}$ & $87 \mathrm{Bbc}$ & $66 \mathrm{Bd}$ & $33 \mathrm{Be}$ & $17 \mathrm{Bf}$ & $10 \mathrm{Bf}$ & - & $60 \mathrm{~B}$ \\
\hline \multirow[t]{2}{*}{ Média } & & $95 \mathrm{a}$ & $95 \mathrm{a}$ & $92 \mathrm{~b}$ & $93 a b$ & $78 \mathrm{c}$ & $45 \mathrm{~d}$ & $31 \mathrm{e}$ & $21 \mathrm{f}$ & & \\
\hline & \multicolumn{11}{|c|}{ Massa de resíduos $\left(\mathrm{t} \mathrm{ha}^{-1}\right)$} \\
\hline SRA & - & $4,7 \mathrm{Aa}$ & 4,6 $\mathrm{Aa}$ & 4,1 Aab & $3,1 \mathrm{Abc}$ & $2,9 \mathrm{Ac}$ & $2,5 \mathrm{Ac}$ & $2,2 \mathrm{Ac}$ & 0,9 Acd & - & $3,1 \mathrm{~A}$ \\
\hline SRE & - & $4,4 \mathrm{Aa}$ & $4,2 \mathrm{Aa}$ & $2,6 \mathrm{Bb}$ & $2,4 \mathrm{Abc}$ & 1,6 Bbcd & 1,6 Acd & 0,7 Bde & $0,3 \mathrm{Ae}$ & - & $2,2 \mathrm{~B}$ \\
\hline Média & & $4,6 \mathrm{a}$ & $4,4 \mathrm{a}$ & $3,3 \mathrm{~b}$ & $2,8 \mathrm{bc}$ & $2,3 \mathrm{~cd}$ & $2,0 \mathrm{de}$ & $1,4 \mathrm{e}$ & $0,6 \mathrm{f}$ & & \\
\hline
\end{tabular}

SRA: solo coberto por resíduo de azevém; SRE: solo coberto por resíduo de ervilhaca; SEA: solo escarificado com raízes de azevém; SEE: solo escarificado com raízes de ervilhaca; e SDE: solo descoberto escarificado. Letras maiúsculas comparam os tratamentos em cada teste de chuva; e letras minúsculas comparam os testes de chuva em cada tratamento ( $p<0,05)$.

no SEA após a escarificação (embora sem diferença estatística) deve-se à maior agregação proporcionada pelas raízes do azevém. As gramíneas são mais eficientes na formação e no aumento da estabilidade dos agregados do que as leguminosas, em razão da maior densidade de raízes que promove a aproximação das partículas pela pressão ao crescerem, conforme Brandão \& Silva (2012).

$\mathrm{O}$ decréscimo do índice $\mathrm{RR}$ foi maior após a aplicação do teste 1 de chuva (25\%) do que a redução ocorrida após a aplicação de todas as demais chuvas (47\%), na média dos tratamentos SEA, SEE e SDE (Quadro 5). Esses resultados concordam com os encontrados por Cogo (1981) e Zoldan Júnior et al. (2008). Segundo Römkens \& Wang (1986), a rápida diminuição da rugosidade após a primeira chuva é por causa da diminuição da porosidade pelo selamento superficial, pela quebra e desagregação de torrões após o umedecimento e, em menor grau, pela deposição de sedimentos nas microdepressões e assentamento do solo.

Individualmente, a diminuição do RR para os tratamentos SEA, SEE e SDE, após o teste 1 de chuva, foi respectivamente 24, 16 e $34 \%$ (Quadro 5). O maior decréscimo no SDE é explicado pelo fato de o solo ter sido mantido constantemente descoberto e periodicamente revolvido, o que fez diminuir o teor de matéria orgânica e a resistência dos agregados à ação da água (Quadro 1), como verificado também por Bertol et al. (2006). A maior diminuição de RR no SEA, em relação ao SEE, justifica-se, provavelmente, pela maior rugosidade inicial do SEA em relação à encontrada no SEE, discordando do encontrado por Bertol et al. (2006). Esses autores observaram correlação entre a persistência dos agregados (DMP e DMG) e a persistência da rugosidade superficial do solo, em que a correlação foi melhor na aveia do que no milho.

O decaimento da rugosidade superficial ao acaso em razão da erosividade acumulada está demonstrado na figura 1 , indicando maior decréscimo do $R R$ no teste de chuva inicial do que nos demais testes, principalmente nos tratamentos SEA e SDE, concordando com Zoldan Junior et al. (2008). Os coeficientes de decaimento foram semelhantes aos encontrados por Zoldan Junior et al. (2008) e inferiores aos encontrados por Eltz \& Norton (1997), provavelmente pela diferença dos solos estudados quanto aos seus constituintes. No tratamento SEE, houve diminuição levemente maior após o teste 2 de chuva, equivalente a $19 \%$, em relação ao decréscimo ocorrido após o teste 1, que foi de $16 \%$. Isso é explicado pelo fato de o solo apresentar-se com baixa resistência à desagregação nesse tratamento em relação aos demais. Assim, o RR diminuiu do teste 1 ao teste 8 de chuva nos tratamentos SEA e SEE; entretanto, no SDE, houve leve aumento do índice de rugosidade a partir do teste 7. Esse aumento é explicado pela formação de sulcos na superfície do solo, visualizada pelos autores durante a aplicação das chuvas. Segundo Paz-Ferreiro et al. (2008), esses sulcos são contabilizados no valor do índice $R R$ pelo programa de cálculo.

Os tratamentos SRA e SRE apresentaram valores relativamente altos de massa de resíduos após o manejo das culturas, com 4,7 e 4,4 t ha ${ }^{-1}$, respectivamente (Quadro 5), decorrentes, provavelmente, das favoráveis condições climáticas ocorridas no período experimental e das adequadas condições físicas e químicas do solo. 
Após o teste 1 de chuva simulada, a diminuição da massa residual do SRA e SRE foi pequena, reduzindo respectivamente 4 e $5 \%$ da massa total inicial (Figura 2a), provavelmente pelo pouco contato dos resíduos com a superfície do solo. Após o teste 2 de chuva, o decaimento foi maior no tratamento $\operatorname{SRE}(37 \%)$ em relação ao SRA (15 \%), efeito esse ocasionado pela menor relação $\mathrm{C} / \mathrm{N}$ da ervilhaca em relação ao azevém (Gilmour et al., 1998). O decaimento mais pronunciado da massa de resíduo do azevém aconteceu somente entre os testes 7 e 8 de chuva, ou seja, quase um ano após a aplicação do teste 1, com uma perda de $26 \%$ de massa no intervalo entre esses dois testes.

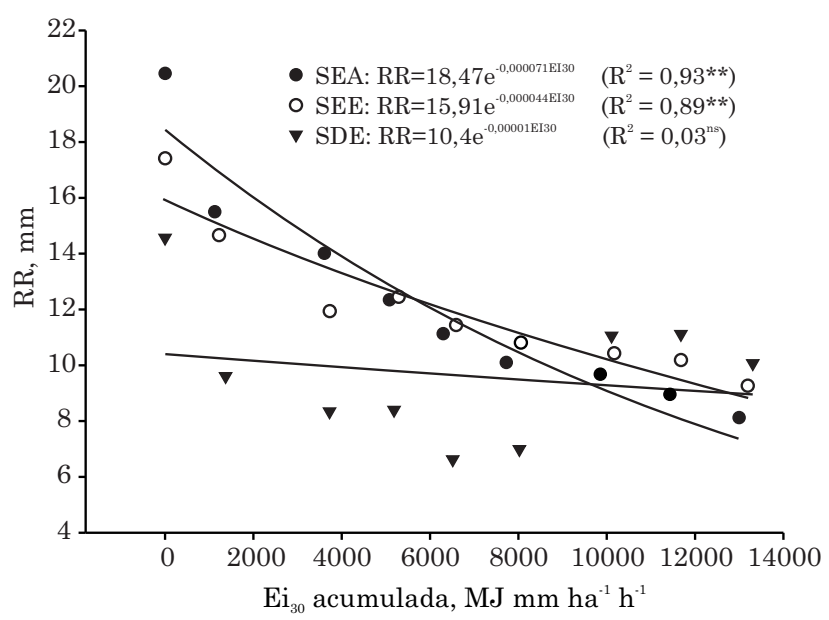

Figura 1. Relação entre a rugosidade ao acaso (RR) da superfície de um Cambissolo Húmico alumínico léptico e o índice de erosividade das chuvas, $\mathrm{EI}_{30}$, após a realização de uma escarificação em diferentes manejos do solo. SEA: solo escarificado com raiz de azevém; SEE: solo escarificado com raiz de ervilhaca; $\mathrm{e}$ SDE: solo descoberto escarificado.
O tratamento com resíduo de azevém (SRA) proporcionou $10 \%$ a mais de cobertura do solo do que com ervilhaca (SRE) no intervalo entre os testes 1 e 4 de chuva simulada, variando de 20 a $25 \%$ no intervalo entre os testes 5 e 8 (Quadro 5). Essa diferença justificase pela maior quantidade de massa vegetal de azevém e pela sua decomposição mais lenta ao longo do tempo, conforme demonstrada na figura 2a e constatada também por Gilmour et al. (1998), pois a massa seca de resíduos da ervilhaca sempre manteve-se abaixo da massa de azevém. Ainda, segundo Lopes et al. (1987b), o maior número de peças do resíduo cultural de azevém em relação ao de ervilhaca, para a mesma massa vegetal, faz com que o azevém tenha maior capacidade de cobrir o solo, podendo ser comprovado pelas equações potenciais, correlacionando a porcentagem de cobertura do solo com a massa de resíduos (Figura 2b).

Entre os tratamentos, as perdas de solo foram menores no SRA $\left(2,93 \mathrm{t} \mathrm{ha}^{-1}\right)$ do que no SRE e SEA (31,21 e 33,57 tha-1 ${ }^{-1}$, respectivamente), entre os quais não houve diferença; porém, esses diferiram dos tratamentos SEE e SDE, que também foram iguais entre si, com perdas respectivas de 73 e $72,27 \mathrm{t} \mathrm{ha}^{-1}$ (Quadro 6).

As menores perdas de solo encontradas no tratamento SRA em relação aos demais se devem ao efeito protetor do solo pelo resíduo cultural do azevém, que dissipou a energia cinética das gotas de chuva e da enxurrada, reduzindo a capacidade de desagregação e transporte das partículas de solo. Além disso, os resíduos provavelmente funcionaram como um filtro, retendo os sedimentos e evitando seu transporte para fora da área, concordando com Mello et al. (2003), em cujo trabalho as perdas de solo sob semeadura direta foram inferiores às perdas dos tratamentos que receberam preparo do solo. Esse efeito protetor do resíduo de azevém no tratamento SRA prolongou-se até o teste 6 de chuva simulada e, a partir daí, sua eficiência foi reduzida, possivelmente pela redução da massa de resíduo e da cobertura do solo (Quadro 5).
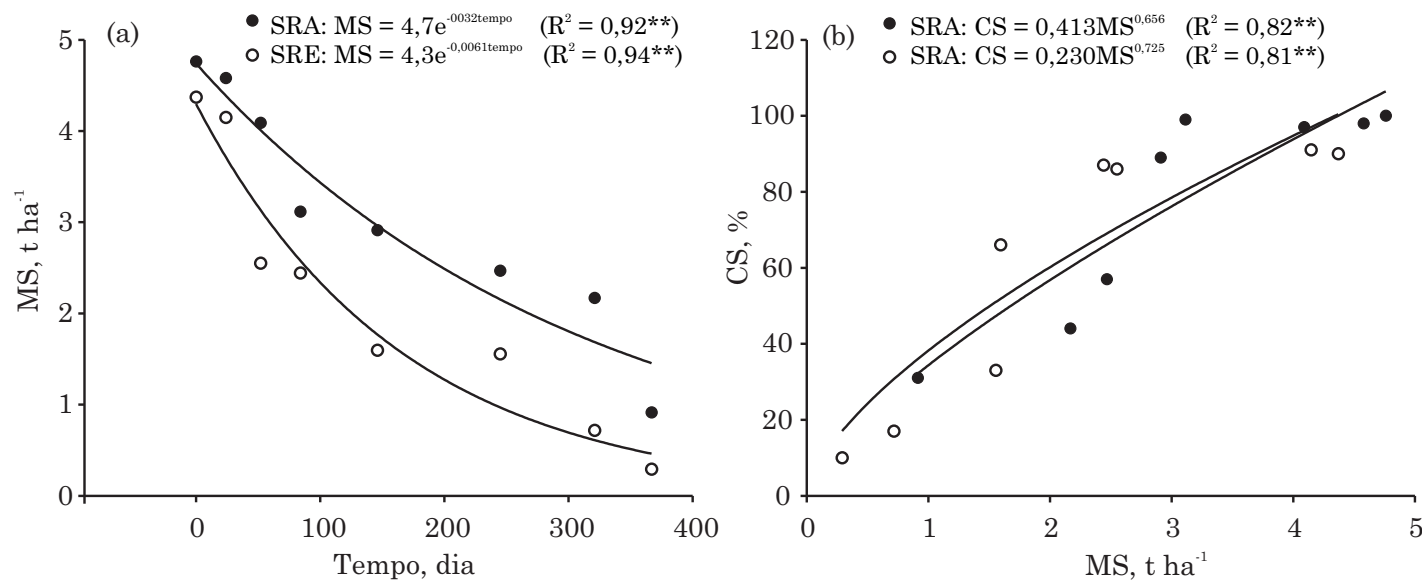

Figura 2. Relação entre a massa vegetal das culturas, MS, e o tempo (a) e relação da cobertura do solo por resíduos culturais, CS, com a massa vegetal das culturas (b), MS, para os tratamentos solo coberto por resíduo de azevém (SRA) e solo coberto por resíduo de ervilhaca (SRE). 
Quadro 6. Perdas de solo e de água nos diferentes tratamentos em cada teste de chuva simulada (T), perda média de cada tratamento e perda média de cada teste de chuva simulada

\begin{tabular}{|c|c|c|c|c|c|c|c|c|c|}
\hline Tratamento & T 1 & T 2 & T 3 & T 4 & T 5 & T 6 & $\mathrm{~T} 7$ & T 8 & Total \\
\hline & \multicolumn{9}{|c|}{ Perda de solo } \\
\hline SRA & $0,05 \mathrm{Cc}$ & 0,03 Dc & $0,04 \mathrm{Cc}$ & 0,03 Dc & $0,04 \mathrm{Cc}$ & 0,06 Dc & $0,61 \mathrm{Cb}$ & $2,08 \mathrm{Ba}$ & $2,93 \mathrm{C}$ \\
\hline SRE & 0,20 Bde & $0,22 \mathrm{BCe}$ & 0,26 Bde & $0,81 \mathrm{Bc}$ & 0,40 Bcd & $0,95 \mathrm{Cb}$ & $10,68 \mathrm{Ba}$ & $17,70 \mathrm{Aa}$ & $31,21 \mathrm{~B}$ \\
\hline SEA & 0,23 Bde & 0,08 CDef & 0,31 Bcb & $0,10 \mathrm{Cf}$ & $0,57 \mathrm{Bc}$ & $5,31 \mathrm{Bb}$ & $10,15 \mathrm{ABab}$ & $16,81 \mathrm{Aa}$ & $33,57 \mathrm{~B}$ \\
\hline SEE & 0,39 Be & $0,29 \mathrm{ABe}$ & $2,11 \mathrm{Ad}$ & $5,69 \mathrm{Ac}$ & 8,32 Abc & 13,60 Aabc & 17,49 Aab & $25,12 \mathrm{Aa}$ & $73,00 \mathrm{~A}$ \\
\hline SDE & $1,03 \mathrm{Ac}$ & $0,45 \mathrm{Ad}$ & $2,50 \mathrm{Ac}$ & $6,80 \mathrm{Ab}$ & $12,01 \mathrm{Aab}$ & $19,56 \mathrm{Aa}$ & 9,66 ABab & $20,27 \mathrm{Aa}$ & $72,27 \mathrm{~A}$ \\
\hline \multirow[t]{2}{*}{ Média } & $0,38 \mathrm{f}$ & $0,21 \mathrm{~g}$ & $1,05 \mathrm{e}$ & $2,69 \mathrm{e}$ & $4,27 \mathrm{~d}$ & $7,90 \mathrm{c}$ & $9,72 \mathrm{~b}$ & $16,40 \mathrm{a}$ & \\
\hline & \multicolumn{9}{|c|}{ Perda de água } \\
\hline SRA & $57 \mathrm{ABab}$ & $48 \mathrm{Aabc}$ & $54 \mathrm{Aab}$ & $41 \mathrm{Bbc}$ & $35 \mathrm{Bc}$ & $48 \mathrm{Babc}$ & $58 \mathrm{Aa}$ & $59 \mathrm{Ba}$ & $50 \mathrm{~B}$ \\
\hline SRE & $56 \mathrm{ABb}$ & $55 \mathrm{Ab}$ & $60 \mathrm{Aab}$ & $51 \mathrm{Ab}$ & $54 \mathrm{Ab}$ & $57 \mathrm{ABb}$ & $69 \mathrm{Aab}$ & $73 \mathrm{Aa}$ & $59 \mathrm{~A}$ \\
\hline SEA & $73 \mathrm{Aab}$ & $63 \mathrm{Abc}$ & $60 \mathrm{Abc}$ & $49 \mathrm{ABc}$ & $62 \mathrm{Abc}$ & $60 \mathrm{ABbc}$ & $72 \mathrm{Aab}$ & $81 \mathrm{Aa}$ & $65 \mathrm{~A}$ \\
\hline SEE & $68 \mathrm{ABab}$ & $61 \mathrm{Ab}$ & $67 \mathrm{Aab}$ & $55 \mathrm{ABb}$ & $63 \mathrm{Ab}$ & $63 \mathrm{ABb}$ & $71 \mathrm{Aab}$ & $80 \mathrm{Aa}$ & $66 \mathrm{~A}$ \\
\hline SDE & $52 \mathrm{Bc}$ & $49 \mathrm{Ac}$ & $50 \mathrm{Ac}$ & $57 \mathrm{ABbc}$ & $66 \mathrm{Abc}$ & $71 \mathrm{Aab}$ & $73 \mathrm{Aab}$ & $83 \mathrm{Aa}$ & $63 \mathrm{~A}$ \\
\hline Média & $61 \mathrm{bc}$ & $55 \mathrm{~cd}$ & $58 \mathrm{~cd}$ & $50 \mathrm{~d}$ & $56 \mathrm{~cd}$ & $60 \mathrm{c}$ & $69 \mathrm{ab}$ & $75 \mathrm{a}$ & \\
\hline
\end{tabular}

SRA: solo coberto por resíduo de azevém; SRE: solo coberto por resíduo de ervilhaca; SEA: solo escarificado com raiz de azevém; SEE: solo escarificado com raiz de ervilhaca; e SDE: solo descoberto escarificado. Letras maiúsculas comparam os tratamentos em cada teste de chuva; e letras minúsculas comparam os testes de chuva em cada tratamento $(p<0,05)$.

As perdas de solo foram maiores no tratamento SRE do que no SRA em todos os testes de chuva, cuja diferença foi 10,6 vezes no total do período experimental (Quadro 6). Essa diferença explica-se pela maior capacidade do resíduo de azevém em cobrir o solo. Além disso, esse resíduo apresenta maior eficácia do que o de ervilhaca para reter os sedimentos maiores; suas raízes apresentam maior eficácia na estruturação do solo do que as de ervilhaca, conforme foi constatado por Luciano et al. (2009). Isso conferiu ao solo maior resistência ao sulcamento pela erosão, conforme constatado por De Baets \& Poesen (2010), em que maior densidade de raízes conferiu menor erodibilidade ao solo. Esses dados concordaram também com os de Lopes et al. (1987a), que ao trabalharem com resíduos de trigo (Triticum aestivum), milho e soja, encontraram distinta eficácia desses resíduos em reduzir a erosão hídrica. A justificativa foi de que o resíduo de trigo apresentou maior número de peças do que os outros resíduos, mantendo maior contato com a superfície do solo e, com isso, cobrindo mais a superfície e filtrando os sedimentos com maior eficácia.

O tratamento SEA apresentou menor perda de solo (33,6 t ha-1) do que o SEE (73 t ha-1), em razão da diferença de cobertura (Quadro 5) e, principalmente, distinta agregação (Quadro 1) e diferente ação das raízes, concordando com De Baets \& Poesen (2010) e Barbosa et al. (2010). Esses autores afirmaram que as gramíneas têm maior capacidade do que as leguminosas de agregar o solo na camada superficial onde se concentram as raízes, diminuindo a quantidade e o diâmetro dos sedimentos erodidos.
Os tratamentos que apresentaram as maiores perdas de solo foram o SEE e SDE, com perdas totais de 73 e 72,3 t ha $^{-1}$, respectivamente, ou seja, 25 vezes maiores do que aquela verificada no tratamento SRA $\left(2,93 \mathrm{t} \mathrm{ha}^{-1}\right)$. A elevada perda total de solo no SDE é explicada pela baixa resistência do solo à erosão, consequência da inexistência de cultivo e consequentemente cobertura do solo, concordando com Schick et al. (2000) e Mello et al. (2003). Segundo Bertol et al. (2008), a presença de culturas tem efeito positivo na conservação do solo por causa da sua influência na agregação, resistência e proteção do solo, pois, mesmo quando incorporados, os resíduos contribuem para a sua agregação. Na ausência de cultivo, há diminuição gradativa da matéria orgânica e atividade biológica do solo, refletindo em menor estabilidade dos agregados e tornando o solo mais susceptível à erosão. A mesma argumentação serve para o tratamento SEE, pois a superfície do solo apresentava baixa cobertura. Além disso, as raízes da ervilhaca são pouco eficientes na agregação do solo, pois apresentam pouca massa e rápida decomposição. Assim, em um solo pouco coberto e com baixa resistência, as gotas de chuva, ao impactarem a superfície, diminuem a rugosidade, selam a superfície e a água forma sulcos onde a enxurrada aumenta o volume e a velocidade (Bertol et al., 1989).

Relacionando os dados de perda de solo com os de erosividade das chuvas (Figura 3), o modelo exponencial do tipo $\mathrm{y}=\mathrm{e}^{\mathrm{bx}}$ ajustou-se aos dados, com exceção do tratamento SRA, indicando que a taxa de perda de solo se elevou com o aumento da erosividade das chuvas nos três tratamentos, diminuindo com o 
aumento da consolidação do solo. Isso demonstrou elevada degradação física e susceptibilidade do solo nos outros tratamentos em relação ao SRA, em razão da menor proteção por resíduos culturais, no caso do SRE, e maior exposição do solo ao impacto direto das gotas de chuva, no caso dos tratamentos escarificados (SEA, SEE e SDE). Tais condições de superfície favoreceram a desagregação do solo e o aumento do sulcamento, conforme constatado por Bertol et al. (2008).

$\mathrm{Na}$ figura 4, demonstra-se a relação entre as perdas de solo com a cobertura por resíduos culturais

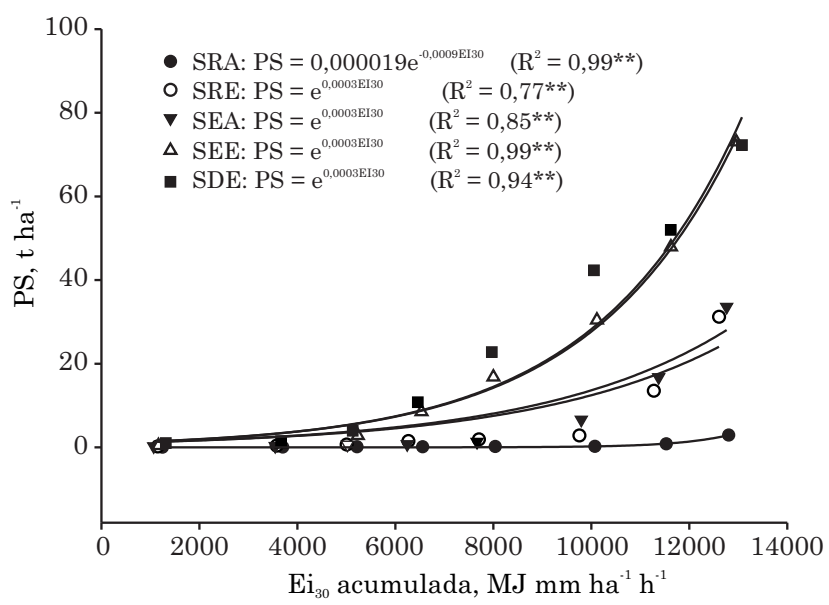

Figura 3. Relação das perdas de solo por erosão hídrica, PS, e o índice de erosividade das chuvas, $\mathrm{EI}_{30}$, em diferentes manejos do solo. SRA: solo coberto por resíduo de azevém; SRE: solo coberto por resíduo de ervilhaca; SEA: solo escarificado com raiz de azevém; SEE: solo escarificado com raiz de ervilhaca; e SDE: solo descoberto escarificado.

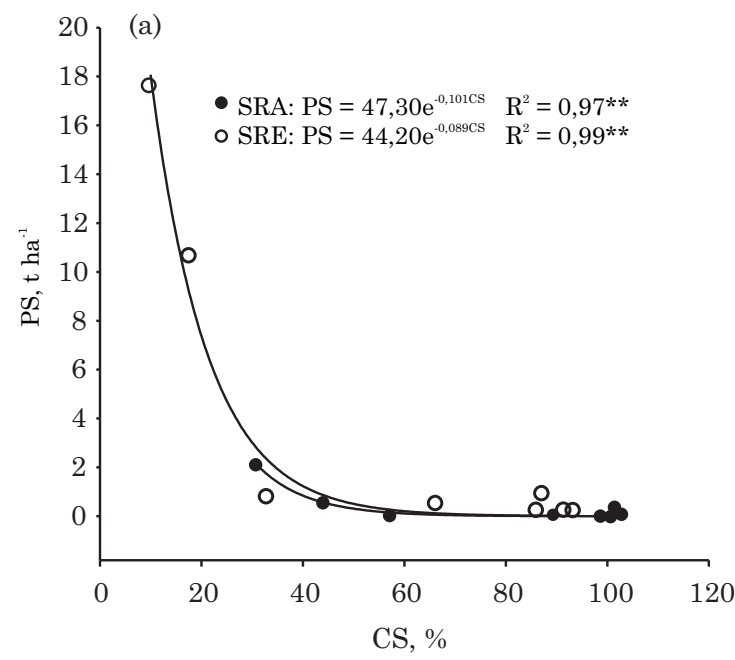

(a) e com a rugosidade superficial ao acaso (b). Ambas as condições de superfície correlacionaram-se inversamente com as perdas de solo $\left(\mathrm{R}^{2}\right.$ entre $0,97 \mathrm{e}$ $0,99 \%)$. Notou-se que, independentemente da condição de superfície, a cultura do azevém foi a mais eficiente na proteção à erosão hídrica, em razão de a maior capacidade das gramíneas em cobrir o solo (Lopes et al., 1987a) e de estruturar e aumentar a sua capacidade em resistir à desagregação (Dechen et al.,1981; Barbosa et al., 2010; Brandão \& Silva, 2012). Ainda nesta figura, pode-se observar a maior importância da estruturação do solo pelas raízes nas perdas desse em um solo rugoso, pois essas perdas foram distintas nos tratamentos em situações de rugosidade similar. Ao contrário desse comportamento, no geral, as perdas de solo nos tratamentos cobertos por resíduos mantiveram-se baixas e similares quando os solos apresentaram coberturas semelhantes, concordando com Norton et al. (1985), pois a cobertura do solo é muito mais importante para explicar as perdas de solo do que a rugosidade superficial.

Entre os tratamentos, para as perdas de água, apenas o SRA diferiu dos demais (Quadro 6). A não diferença estatística para a maioria dos tratamentos estudados justifica-se pela uniformidade do teor de água no solo, antecedente às chuvas simuladas aplicadas (Quadro 4) e à limitada capacidade natural de infiltração de água do solo, que, quando submetido a chuvas intensas e de longa duração, a taxa de enxurrada tende a se igualar em todos os tratamentos, inibindo os efeitos desses na enxurrada, conforme argumentado por Schick et al. (2000). A maior eficiência do SRA em relação ao SRE deve-se à maior capacidade das gramíneas em reduzir a erosão, pois, além de produzirem maior quantidade de resíduos, têm maior capacidade de reestruturação do solo por causa da melhor produção e distribuição de seu sistema

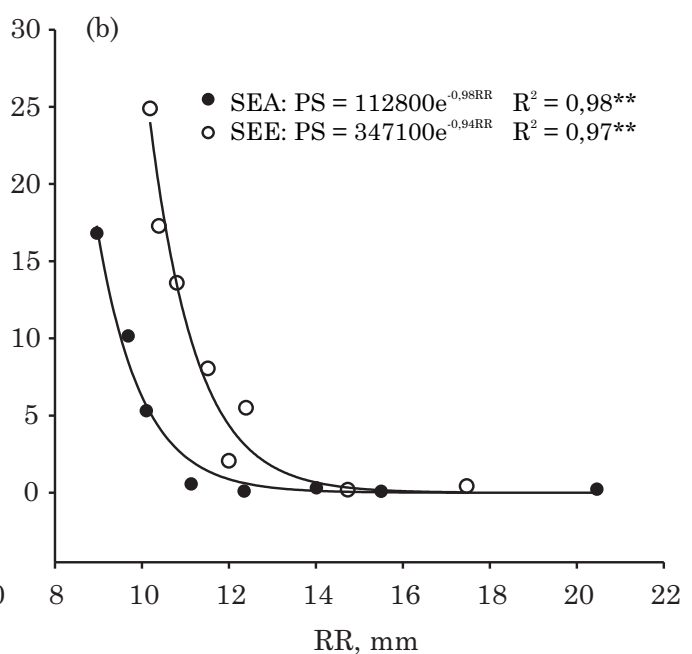

Figura 4. Relação das perdas de solo, PS, com a cobertura por resíduos culturais, CS (a), e com a rugosidade superficial ao acaso, RR (b), para os tratamentos: solo coberto por resíduo de azevém (SRA); solo coberto por resíduo de ervilhaca (SRE); solo escarificado com raiz de azevém (SEA); e solo escarificado com raiz de ervilhaca (SEE). 
radicular, tornando-o mais resistente à desagregação pelo impacto das gotas da chuva e enxurrada associada, resultando em menores perdas, concordando com Dechen et al. (1981), porém discordando dos valores encontrados por Luciano et al. (2009).

Além do fato de o tratamento SRA ter perdido menos água do que os demais, na média dos testes de chuva, o tratamento SRE perdeu, numericamente, menos água do que os tratamentos em que o solo foi escarificado, embora sem diferença estatística (Quadro 6). Isso demonstrou maior eficiência dos resíduos culturais mantidos na superfície, na condição sem preparo do solo, em reduzir as perdas de água em relação à condição em que o solo foi preparado por uma escarificação, após a parte aérea dos resíduos ter sido removida, mantendo-se apenas as soqueiras com as raízes. Esses dados concordam com os encontrados por Schick et al. (2000), em que a semeadura direta perdeu menos água do que o solo revolvido mecanicamente e contrastam com os resultados encontrados por Mello et al. (2003), em que a escarificação proporcionou menor perda de água do que os tratamentos com resíduos sobre a superfície.

Entre os tratamentos em que o solo foi escarificado, a menor perda de água foi encontrada no SDE (Quadro 6). Provavelmente, isso foi por causa de o solo ter sido revolvido frequentemente com aração nos trabalhos anteriores e depois escarificado imediatamente antes de iniciar as chuvas, fato esse comprovado pela maior macroporosidade desse tratamento, em comparação às encontradas nos outros tratamentos escarificados (Quadro 1). Entretanto, Bertol et al. (2008) obtiveram perdas inferiores de água em um solo sem cultivo, descoberto e escarificado em comparação a outros tratamentos em que o solo foi cultivado e escarificado.

Com exceção do tratamento SRA, as perdas de água apresentaram tendência em aumentar com o passar dos testes de chuva (Quadro 6), ressalvando-se o efeito do teor de água no solo antecedente às chuvas. Essa tendência de aumento ocorreu em razão da diminuição da rugosidade superficial nos tratamentos em que o solo foi escarificado, da diminuição da cobertura por resíduos culturais nos tratamentos em que os resíduos foram mantidos na superfície do solo e, principalmente, por causa do selamento superficial no solo descoberto conforme demonstrado por Bertol et al. (1989). O selamento superficial, segundo Dalla Rosa et al. (2013), não ocorre somente na superfície descoberta, mas também na coberta em razão da ação do cisalhamento da enxurrada.

O resíduo de azevém mantido sobre a superfície do solo no tratamento SRA propiciou menor perda de água do que o de ervilhaca no SRE. No entanto, não houve influência das culturas para as perdas de água nos tratamentos em que o solo foi escarificado, concordando com Laflen \& Colvin (1981). Esses autores demonstraram que distintos preparos de solo influenciam mais as perdas de água do que diferentes resíduos culturais.

\section{CONCLUSÕES}

1. A rugosidade é maior no solo cultivado e escarificado do que no sem cultivo.

2. O azevém produz maior quantidade de resíduo na parte aérea, resiste mais à decomposição e cobre mais o solo do que a ervilhaca; a diferença de cobertura do solo é $17 \%$, na média de um ano.

3. As perdas de solo são menores sob resíduo de azevém do que de ervilhaca, cuja diferença é $91 \%$; sob resíduo de azevém, essas perdas são iguais às ocorridas no solo escarificado contendo apenas as raízes da cultura; e, nessas duas condições, as mesmas perdas são menores do que as ocorridas no solo escarificado na presença das raízes de ervilhaca, cuja diferença é $54 \%$.

4. As perdas de água pela enxurrada seguem a mesma tendência das perdas de solo, porém com menor magnitude de diferença do que essas.

5. A rugosidade ao acaso e a cobertura do solo por resíduos de azevém e ervilhaca diminuem exponencialmente com o aumento da erosividade da chuva, enquanto as perdas de solo aumentam exponencialmente com o aumento da erosividade da chuva e reduzem exponencialmente com o aumento da cobertura do solo e da rugosidade superficial ao acaso.

\section{AGRADECIMENTO}

À Fundação de Amparo à Pesquisa e Inovação do Estado de Santa Catarina - FAPESC, pela parte dos recursos financeiros concedidos para a realização deste trabalho.

\section{LITERATURA CITADA}

ALLMARAS, R.R.; BURWELL, R.E. \& LARSON, W.E. Total porosity and roughness of the interrow zone as influenced by tillage. Washington, ARS/USDA. 1966. 22p. (Cons. Res. Report, 7)

BARBOSA, F.T.; BERTOL, I.; LUCIANO, R.V. \& PAZFERREIRO, J. Proporção e tamanho de sedimentos e teor de carbono orgânico na enxurrada e no solo para dois cultivos e duas formas de semeadura. R. Bras. Ci. Solo, 34:1701-1710, 2010. 
BERTOL, I.; COGO, N.P. \& LEVIEN, R. Cobertura morta e métodos de preparo do solo na erosão hídrica em solo com crosta. R. Bras. Ci. Solo, 13:373-379, 1989.

BERTOL, I.; LEITE, D. \& ZOLDAN JUNIOR, W.A. Decomposição do resíduo de milho e variáveis relacionadas. R. Bras. Ci. Solo, 28:369-375, 2004.

BERTOL, I.; AMARAL, A.J.; VÁZQUEZ, E.V.; GONZÁLEZ, A.P.; BARBOSA, F.T. \& BRIGNONI, L.F. Relações da rugosidade superficial do solo com o volume de chuva e com a estabilidade de agregados em água. R. Bras. Ci. Solo, 30:543-553, 2006.

BERTOL, I.; ZOLDAN JUNIOR, W.A.; FABIAN, E.L.; ZAVASCHI, E.; PEGORARO, R. \& PAZ GONZÁLES, A. Efeito de escarificação e da erosividade de chuvas sobre algumas variáveis de valores de erosão hídrica em sistemas de manejo de um Nitossolo Háplico. R. Bras. Ci. Solo, 32:747-757, 2008.

BERTOL, I.; BERTOL, C. \& BARBOSA, F.T. Simulador de chuva tipo empuxo com braços movidos hidraulicamente: Fabricação e calibração. R. Bras. Ci. Solo, 36:1905-1910, 2012.

BRAMORSKI, I.; MARIA, I.C.; SILUA, R.L. \& CRESTANA, S. Relations between soil surface roughness, tortuosity, tillage treatments, rainfall intensity and soil and water losses from a Red Yellow Latosol. R. Bras. Ci. Solo, 36:1291-1297, 2012.

BRANDÃO, E.D. \& SILVA, I.F. Formação e estabilização de agregados pelo sistema radicular de braquiária em um Nitossolo Vermelho. Ci. Rural, 42:1193-1199, 2012.

COGO, N.P. Effect of residue cover, tillage-induced roughness and slope length on erosion and related parameters. West Lafayette, Purdue University, 1981. 346p. (Tese de Doutorado)

CORREA, I.M.C.; BERTOL, I.; RAMOS, J.C. \& TAKIZAWA, M.M. Rugosidade da superfície de um Cambissolo Húmico relacionada com o preparo e compactação do solo sob chuva natural. R. Bras. Ci. Solo, 36:567-576, 2012 .

DALLA ROSA, J.; COOPER, M.; DARBOUX, F.; MEDEIROS, J.C. \& MEDEIROS, J.C. . Processo de formação de crostas superficiais em razão de sistemas de preparo do solo e chuva simulada. R. Bras. Ci. Solo, 37:400-410, 2013.

DE BAETS, S. \& POESEN, J. Empirical models for predicting the erosion-reducing effect of plant roots during concentrated flow. Geomorphology, 118:425-432, 2010.

DECHEN, S.L.F.; LOMBARDI NETO, F. \& CASTRO, O.M. Gramíneas e leguminosas e seus restos culturais no controle da erosão em Latossolo. R. Bras. Ci. Solo, 5:133137, 1981.

ELLISON, W.D. Soil erosion studies. Agric. Eng., 28:145147, 197-201, 245-248, 297-300, 349-351, 402-405, 442444, 1947.

ELTZ, F.L.F. \& NORTON, L.D. Surface roughness changes as affected by rainfall erosivity, tillage, and canopy cover. Soil Sci. Soc. Am. J., 61:1746-1755, 1997.
EMPRESA BRASILEIRA DE PESQUISA AGROPECUÁRIA - EMBRAPA. Sistema brasileiro de classificação de solos. Brasília, Embrapa-CNPS, 1999. 412p.

FOSTER, G.R.; McCOOL, D.K.; RENARD, K.G. \& MOLDENHAUER, W.C. Conversion of the universal soil loss equation to SI metric units. Soil Water Conserv., 36:355-359, 1981

GILMOUR, J.T.; MAUROMOUSTAKOS, A.; GALE, P.M. \& NORMAN, R.J. Kinetics of crop residue decomposition: Variability among crops and years. Soil Sci. Soc. Am. J., 62:750-755, 1998 .

INSTITUTO AGRONÔMICO DO PARANÁ - IAPAR. Recomendações gerais do encontro sobre uso do simulador de chuva em pesquisa de conservação de solo no Brasil. In: ENCONTRO NACIONAL SOBRE PESQUISA DE EROSÃO COM SIMULADORES DE CHUVA, 1., Londrina, 1975. Anais... Londrina, 1975. p.107-120.

KAMPHORST, E.C.; JETTEN, V.; GUÉRIF, J.; PITKANEN, J.; IVERSEN, N.V.; DOUGLAS, J.T. \& GONZÁLES, A.P. Predicting depressional storage from soil roughness. Soil Sci. Soc. Am. J., 64:749-758, 2000.

LAFLEN, J.M. \& COLVIN, T.S. Effect of crop residue on soil loss from continuous row cropping. Trans. Am. Sci. Agric. Eng., 24:605-609, 1981.

LITTEL, R.C.; PENDERGAST, J. \& NATARAJAN, R. Modelling covariance structure in the analysis of repeated measures data. Statistics Med., 19:1793-1819, 2000.

LIÑARES, L.M. \& CASTRO, T.M.M. Medida de la rugosidad del suelo en terrenos de cultivo. In: ORTIZ, G.A. \& FRANCH, S.F., ed. REUNIÓN NACIONAL DE GEOMORFOLOGIA, 5., Barcelona, 1998. Actas... Barcelona, 1998. p.731-734.

LOPES, P.R.C.; CASSOL, E.A. \& COGO, N.P. Influência da cobertura vegetal morta na redução da velocidade de enxurrada e na distribuição de tamanho de sedimentos transportados. R. Bras. Ci. Solo, 11:193-197, 1987a.

LOPES, P.R.C.; COGO, N.P. \& LEVIEN, R. Eficácia relativa de tipo e quantidade de resíduos culturais espalhados uniformemente sobre o solo na redução da erosão hídrica. R. Bras. Ci. Solo, 11:71-75, 1987b.

LUCIANO, R. V.; BERTOL, I. ; BARBOSA, F. T. ; VÁZQUEZ, E. V. ; FABIAN, E. L.. Perdas de água e solo por erosão hídrica em duas direções de semeadura de aveia e ervilhaca. R. Bras. Ci. Solo, 33:669-676, 2009.

MANNERING, J.V. \& MEYER, L.D. The effects of various rates of surface mulch on infiltration and erosion. Soil Sci. Soc. Am. J., 27:84-86, 1962.

MELLO, E.L.; BERTOL, I.; ZAPAROLLI, V. \& CARRAFA, M.R. Perdas de solo e água em diferentes sistemas de manejo de um Nitossolo Háplico submetido à chuva simulada. R. Bras. Ci. Solo, 27:901-909, 2003.

MEYER, L.D. An investigation of methods for simulating rainfall on standard runoff plots and study of the drop size, velocity, and kinetic energy of selected spray nozzles. West Lafayette, USDA-ARS-SWCRD-ESWMRB and Purdue University, 1958. 43p. (Special Report, 81) 
MIRANDA, J.G.V. Análisis fractal del microrrelieve del suelo. A Coruña, Universidad da Coruña, 2000. 313p. (Tese de Doutorado)

NORTON, L.D.; COGO, N.P. \& MOLDENHAUER, W.C. Effectiveness of mulch in controlling soil erosion. In: ELSWAIFY, S.A.; MOLDENHAUER, W.C. \& LO, A., orgs. Soil erosion and conservation. Ankeny, SCSA, 1985. v.1, p.598-606.

PAZ-FERREIRO, J.; BERTOL, I. \& VIDAL VÁZQUEZ, E. Quantification of tillage, plant cover, and cumulative rainfall effects on soil surface microrelief by statistical, geostatistical and fractal indices. Nonlinear Proc. Geophys., 15:575-590, 2008.

RÖMKENS, M.J.M. \& WANG, J.Y. Effect of tillage on soil roughness. Trans. Am. Soc. Agric. Eng., 29:429-433, 1986.

SCHICK, J.; BERTOL, I.; BATISTELA, O. \& BALBINOT JUNIOR, A.A. Erosão hídrica em Cambissolo Húmico submetido a diferentes sistemas de preparo e cultivo do solo: I. Perdas de solo e água. R. Bras. Ci. Solo, 24:427436, 2000.

SCHICK, J.; BERTOL, I.; COGO, N.P. \& PAZ GONZÁLEZ, A. Erosividade das chuvas de Lages (SC). R. Bras. Ci. Solo, 2014. (No prelo)
SLONEKER, L.L. \& MOLDENHAUER, W.C. Measuring the amounts of crop residue remaining after tillage. J. Soil Water Conserv., 32:231-236, 1977.

VOLK, L.B.S. \& COGO, N.P. Relações entre tamanho de sedimentos erodidos, velocidade da enxurrada, rugosidade superficial criada pelo preparo e tamanho de agregados em solo submetido a diferentes manejos. R. Bras. Ci. Solo, 33:1459-1471, 2009.

WAGNER, L.E. Profile meter program. Documentation. Washington, United States/Departament of Agriculture/ Agricultural Research Service/Wind Erosion Research Unit, 1992. 27p.

WAGNER, L.E. \& YIMING, YU. Digitization of profile meter photoghaphs. Trans. Am. Soc. Agric. Eng., 34:412-416, 1991.

WISCHMEIER, W.H. \& SMITH, D.D. Predicting rainfall erosion losses: a guide to conservation planning. Washington, USDA, 1978. 58p. (Agricultural Handbook, 537)

WOLFINGER, R.D. Covariance structure selection in general mixed models. Commun. Statist. Simul. Comput., 22:10791106, 1993.

ZOLDAN JUNIOR, W.A.; BERTOL, I.; PEGORARO, R.; FABIAN, E.L.; ZAVASCHI, E. \& VIDAL VÁZQUEZ, E. Rugosidade superficial do solo formada por escarificação e afetada pela erosividade da chuva. R. Bras. Ci. Solo, 32:353-362, 2008. 